NASA Technical Memorandum 107212

\title{
Atomic Oxygen Durability Testing of an International Space Station Solar Array Validation Coupon
}

Mark J. Forkapa and Curtis R. Stidham

NYMA, Inc.

Brook Park, Ohio

Bruce A. Banks and Sharon K. Rutledge

Lewis Research Center

Cleveland, Ohio

David H. Ma

Lockheed Martin Missiles \& Space Company

Sunnyvale, California

Edward A. Sechkar

Cleveland State University

Cleveland, Ohio

Prepared for the

Third International Conference on Protection of Materials and Structures from the Low Earth Orbit Space Environment sponsored by the University of Toronto

Toronto, Canada, April 25-26, 1996

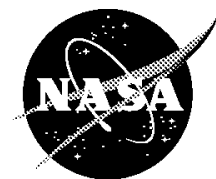

National Aeronautics and

Space Administration 
Trade names or manufacturers' names are used in this report for identification only. This usage does not constitute an official endorsement, either expressed or implied, by the National Aeronautics and Space Administration. 


\title{
Atomic Oxygen Durability Testing of an International Space Station Solar Array Validation Coupon
}

\author{
Mark J. Forkapa \\ Curtis R. Stidham \\ NYMA Incorporated \\ Cleveland, Ohio \\ Bruce A. Banks \\ Sharon K. Rutledge \\ NASA Lewis Research Center \\ Cleveland, Ohio \\ David H. Ma \\ Lockheed Martin Missiles \& Space Company \\ Sunnyvale, California \\ Edward A. Sechkar \\ Cleveland State University \\ Cleveland, Ohio
}

\section{Abstract}

An International Space Station solar array validation coupon was exposed in a directed atomic oxygen beam for space environment durability testing at the NASA Lewis Research Center. Exposure to atomic oxygen and intermittent tensioning of the solar array were conducted to verify the solar array's durability to low Earth orbital atomic oxygen and to the docking threat of plume loading both of which are anticipated over its expected mission life of fifteen years.

The validation coupon was mounted on a specially designed rotisserie. The rotisserie mounting enabled the solar and anti-solar facing side of the array to be exposed to directed atomic oxygen in a sweeping arrival process replicating space exposure. The rotisserie mounting also enabled tensioning, in order to examine the durability of the array and its hinge to simulated plume loads.

Flash testing to verify electrical performance of the solar array was performed with a solar simulator before and after the exposure to atomic oxygen and tensile loading. Results of the flash testing indicated little or no degradation in the solar array's performance. Photographs were also taken of the array before and after the durability testing and are included along with comparisons and discussions in this report. The amount of atomic oxygen damage appeared minor with the exception of a very few isolated defects. There were also no indications that the simulated plume loadings had weakened or damaged the array, even though there was some erosion of Kapton due to atomic oxygen attack. Based on the results of this testing, it is apparent that the International Space Station's solar arrays should survive the low Earth orbital atomic oxygen environment and docking threats which are anticipated over its expected mission life. 


\section{Introduction}

The International Space Station (ISS) operating in the low Earth orbital (LEO) environment between the altitudes of 333 to $463 \mathrm{Km}$, will be exposed to the damaging environmental effects of atomic oxygen (AO), solar ultraviolet radiation (UV), thermal cycling, and micrometeroid/debris impacts. Of these threats, atomic oxygen is the most damaging to polymeric surfaces such as polyimide Kapton which is one of the primary structural materials of the space station's solar arrays. ${ }^{1,2}$ Atomic oxygen can be detrimental because as a spacecraft travels at high velocities relative to the low Earth orbit environment its surfaces are impacted by atomic oxygen at sufficient energies $(\approx 4.5 \mathrm{eV})$ to readily break chemical bonds. ${ }^{3}$ The resulting oxidation can compromise the integrity of the spacecraft's surfaces by altering their morphology, thermal properties, optical properties, and strength.

An integral component of the ISS's Electric Power System (EPS) are the solar array wings which measure 110 feet long by 37 feet wide. Each solar array wing consists of two array blankets containing 82 hinged solar panels, each with 200 solar cells. ${ }^{4}$ To date great efforts have been made to produce atomic oxygen durable materials for use on the solar array blankets. As a result of these efforts protective coatings, reinforced fiberglass fabric coverlays, processing techniques, and fabrication methods have been developed which have improved the environmental durability of the arrays. ${ }^{5,6,7}$

Currently, $1300 \AA$ A-thick $\mathrm{SiO}_{\mathrm{x}}$ (where, $1.9<\mathrm{x}<2.0$ ) coatings are being used as part of the coverlay laminate to protect the solar array's blanket materials from atomic oxygen attack. Although the $\mathrm{SiO}_{x}$ coatings greatly reduce the amount of erosion and oxidation, scratch or pin window defects in the protective $\mathrm{SiO}_{\mathrm{x}}$ coatings allow oxidation of the underlying polymer, silicone, and fiberglass fabric resulting in atomic oxygen undercutting and oxidation. ${ }^{6}$ Defects are caused by particulate contaminants, surface irregularities, abrasions during handling and processing, and micrometeroid impacts.

Until now, the atomic oxygen durability evaluations of materials for the ISS solar arrays have been based primarily on mass loss and erosion of small test coupons. Although mass loss and erosion studies are excellent methods to determine atomic oxygen durability, they do not fully indicate whether the material has been degraded to the point of mechanical failure. Since the mechanical ability of the array blanket to provide support to the solar cells and printed circuitry is highly dependent on its atomic oxygen durability, it is imperative to conduct a functional test of the array under atomic oxygen attack.

One of the most dramatic loading events the solar arrays will experience is the dynamic and quasi-static loads imparted by the impingement of exhaust fumes from the shuttle while performing docking maneuvers. This plume loading of the arrays is caused by the firing of the shuttle's Reaction Controls System (RCS) and Attitude Control System (ACS) jets, which create typical surface pressures on the order of $68.95 \mathrm{~Pa}\left(0.01 \mathrm{lb} / \mathrm{in}^{2}\right) .{ }^{8}$ The large loads which the solar arrays will experience during shuttle docking maneuvers could cause a mechanical failure of the arrays if atomic oxygen degradation is considerable. 
In order to verify the atomic oxygen durability of the ISS's solar arrays, this paper presents the results of functional testing of an actual solar array validation coupon. The validation coupon was exposed to a directed atomic oxygen beam with sweeping arrival while under normal tensioning. At intermittent points of the array's exposure to atomic oxygen, it was subjected to a simulated plume load by tensioning the array to a specified load. The plume loading was to verify that after degradation due to atomic oxygen exposure the array, especially around its hinged region, would meet the design load requirements. Along with verifying its mechanical durability, the electrical performance of the solar array was also tested in a solar simulator both before and after exposure to the low Earth orbit environmental threats.

The desired atomic oxygen fluence for exposure of the anti-solar side of the array was $5.2 \times 10^{22}$ atoms $/ \mathrm{cm}^{2}$ and $4.4 \times 10^{22}$ atoms $/ \mathrm{cm}^{2}$ for the solar side of the array. The fluence values were based on the expected mission duration of 15 years, consisting of 87,660 orbits. The lower desired fluence for the solar facing side of the array was based on the fact that it will see a lower atomic oxygen fluence than the anti-solar side due to the higher atomic oxygen density present after solar noon impinging upon the anti-solar side of the array.

The study was completed by NYMA Incorporated, the National Aeronautics and Space Administration at the NASA Lewis Research Center in Cleveland, Ohio, and the Lockheed Martin Missiles and Space Company in Sunnyvale, California. Lockheed Martin is responsible for supplying the photovoltaic arrays for use on the ISS.

\section{Apparatus and Test Procedures}

\section{A. Apparatus}

\section{Solar Array Validation Coupon}

A fully functional solar array coupon representing the actual full flight design minus the deployment spring at the hinge was tested for environmental durability to atomic oxygen and plume loading. The array coupon was supplied by the Lockheed Martin Missiles and Space Company and measured $454.7 \mathrm{~mm}$ (17.90 in.) long by $388.4 \mathrm{~mm}(15.29 \mathrm{in}$.) wide. The array was mounted to stainless steel loading bars at each end which allowed installation to the test apparatus and for distribution of the loading (Figures 1a and 1b). The array coupon was comprised of two sections hinged together each of which contained eight, $8 \mathrm{~cm} \times 8 \mathrm{~cm}$, solar cells. The primary surfaces which received the largest flux of atomic oxygen were the doped glass coverslide on the solar side of the array, and a coverlay laminate comprised of Kapton, glass cloth, and silicone adhesive with a protective $\mathrm{SiO}_{\mathrm{x}}$ coating on the anti-solar side. A cross section of the solar array's composition can be found in Figure 2.

\section{Mounting Rotisserie}

The atomic oxygen durability testing of the solar array validation coupon was performed in the NASA Lewis Research Center's (LeRC) atomic oxygen directed beam facility. The validation coupon was mounted in the atomic oxygen exposure facility on a specially designed rotisserie. 
The rotisserie mounting was designed so that the solar and anti-solar facing side of the coupon could be exposed to directed atomic oxygen in a sweeping arrival process replicating space exposure and also to provide a means of tensioning the array. A photograph of the mounting rotisserie can be found in Figure 3. It was desired that the solar array coupon be capable of rotating at two discrete speeds so that the atomic oxygen fluence of each side could be separately controlled. Rotation rates were selected for each side of the array so that the atomic oxygen fluence of each side was fully representative of what will be required of it in space. As mentioned earlier, in orbit, the solar facing side of the array will see a lower atomic oxygen fluence than the anti-solar side due to the higher atomic oxygen density present after solar noon impinging upon the anti-solar side of the array. This difference was achieved in the atomic oxygen directed beam facility by using a stepper-motor and drive system which provided two separate rates of rotation through a sprocket and chain system.

Motion control of the stepper-motor and drive system was provided by a program written in QuickBasic specifically for the test. A mechanical microswitch was used to provide a signal to the motion control software for proper phasing of the rotational speeds so that each side of the solar array coupon was exposed to the proper atomic oxygen fluence. The microswitch was also used to ensure that the solar array was rotating. In the event of a mechanical failure which would cease the rotation of the system, the microswitch would enable the motion control software to sense the problem, cut off power to the drive system, and signal the atomic oxygen source controller to shut off. This prevented non-sweeping and over-exposure to one face of the array.

The rotisserie mounting hardware also provided spring loaded tensioning of the test array coupon so that the proper static preload could be applied and so that simulated plume loading could be performed. Tensioning of the array was supplied by two springs mounted in parallel which were connected to a load cell fastened to the end of a threaded rod. The threaded rod was mounted on a bracket, which was supported by the frame of the rotisserie, and a combination of standard hex nuts was used to adjust the tension of the array. The load cell provided a means to measure the applied force so that the tension of the array could be adjusted to the desired static load (as illustrated in Figure 4).

\section{Atomic Oxygen Facility}

The atomic oxygen facility uses a 1000 watt electron cyclotron resonance (ECR) plasma source operated on oxygen to generate a low energy, broad area, directed beam of primarily oxygen atoms, ions, radicals, and metastables. The kinetic energy of the directed ionized species has been determined, by using a retarding potential analyzer probe, to be below 30 electron volts (eV) with a distribution having peaks occurring at 10.5 and $25 \mathrm{eV} .{ }^{9}$ The chamber pressure during operation of the ECR source is typically below $8.0 \times 10^{-2} \mathrm{~Pa}\left(6.0 \times 10^{-4}\right.$ Torr $)$. Further detailed descriptions of this facility can be found in Reference 9. A photograph of the solar array validation coupon mounted in the rotisserie and installed in the atomic oxygen facility can be found in Figure 5. 


\section{Solar Simulator Facility}

Electrical performance testing of the solar array coupon was conducted in a solar simulation facility at the Lockheed Martin Missiles and Space Company Laboratories in Sunnyvale, California. Flash testing of the array was performed using the Spectrosun Large Area Pulsed Solar Simulator II (LAPSS II) manufactured by Spectrolab Incorporated. It is a complete test system for the electrical evaluation of photovoltaic solar cell arrays under controlled conditions. While intended for large arrays, the LAPSS II system can be used for single solar cells or small groups of cells. The LAPSS II system contains two subsystems: The Pulse Illuminator and the Data Acquisition and Control Unit. The light source which contains two lamps is housed within the Pulse Illuminator and can produce 4 megawatts of power with a stable duration of at least one millisecond.

In normal setup and operation, the target-to-source distance ranges from 9 to $13 \mathrm{~m}$. Calibration is performed at $140 \mathrm{~mW} / \mathrm{cm}^{2}$ measured with $2 \mathrm{~cm}$ square solar cells. The spectral match between 0.4 and 1.4 microns is within a $5 \%$ percent distribution of the curve for air mass zero (AMO) sunlight published in NASA Technical Report R-351. For reliable operation of the LAPSS II the ambient temperature is kept between $15^{\circ}$ and $30^{\circ}$ Celcius. Operator selectable temperature correction can be made on the I-V data to reflect a temperature different from that of the actual test. The light uniformity of the system is better than $0.5 \%$ within a ten centimeter by ten centimeter square in the center of the target area. The calibration measurement is taken from a one centimeter square solar cell.

\section{B. Test Procedures}

\section{Pre-Exposure Procedures}

The atomic oxygen fluence for the durability testing was determined by an effective flux measurement based on mass loss of $2.54 \mathrm{~cm}$ diameter polyimide Kapton $\mathrm{HN}$ witness samples. The in-space erosion yield of Kapton is well known and accepted as a standard means of atomic oxygen flux evaluation. ${ }^{10}$ The effective flux measurement, based on mass loss, is calculated by:

$$
f=\frac{\Delta M}{\rho A_{s} t E_{Y}}
$$

$\mathrm{f}=$ Effective flux $\left(\right.$ atoms $\left./\left(\mathrm{cm}^{2} \cdot \mathrm{sec}\right)\right)$

$\Delta \mathrm{M}=$ Change in witness sample mass $(\mathrm{g})$

$\rho=$ Density $\left(\mathrm{g} / \mathrm{cm}^{3}\right)$

$\mathrm{A}_{s}=$ Sample area $\left(\mathrm{cm}^{2}\right)$

$\mathrm{t}=$ Time (s)

$E_{\mathrm{Y}}=$ Erosion yield $\left(\mathrm{cm}^{3} /\right.$ atom $)$

Based on an atomic oxygen kinetic energy of $4.5 \mathrm{eV}$, the in-space erosion yield for polyimide Kapton $\mathrm{HN}$ is documented as $3 \times 10^{-24} \mathrm{~cm}^{3} /$ atom. . $^{11,12,13,14,15}$ By using the in-space erosion yield the calculated result approximates the in-space flux which would result in the same mass loss. 
Before the actual atomic oxygen exposure of the solar array validation coupon, both stationary and rotating flux tests were performed. The mounting rotisserie for the test was first loaded with a polyimide Kapton sheet to act as a mock array. Kapton witness samples were then mounted in the same locations as they were to be mounted on the actual array. First a static flux test was performed in order to determine the flux at the sample plane. The effective flux was determined to be $1.41 \times 10^{16}$ atoms $/\left(\mathrm{cm}^{2} \cdot \mathrm{sec}\right)$. Once the static flux test results were obtained the effective flux was used to determine the two rotation rates of the test array so that the atomic oxygen fluence of each rotation would result in the same fluence experienced in space by both the solar and anti-solar side of the array. The first step in determining the rotation rates was to determine the average total flux, $\mathrm{f}_{\mathrm{a}}$, arriving on the array surfaces. The average flux was found using the flux from the static test, $f$, and the following cosine relation due to directional and angular effects of the sweeping exposure:

$$
f_{a}=\int_{-\frac{\pi}{2}}^{\frac{\pi}{2}} f \cos \theta d \theta=\frac{2}{\pi} f
$$

$\mathrm{f}_{\mathrm{a}}=$ average flux $\left(\right.$ atoms $\left./\left(\mathrm{cm}^{2} \cdot \mathrm{sec}\right)\right)$

$\mathrm{f}=$ flux $\left(\right.$ atoms $\left./\left(\mathrm{cm}^{2} \cdot \mathrm{sec}\right)\right)$

$\theta=$ angle of incidence (radians)

The average flux, $\mathrm{f}_{\mathrm{a}}$, can also be expressed as:

$$
f_{a}=\frac{F}{T N}
$$

$\mathrm{f}_{\mathrm{a}}=$ average flux $\left(\right.$ atoms $\left./\left(\mathrm{cm}^{2} \cdot \mathrm{sec}\right)\right)$

$\mathrm{T}=$ exposure time / revolution (sec/rev)

$\mathrm{N}=$ number of orbits (number of exposures)

$\mathrm{F}=$ Desired fluence $\left(\right.$ atoms $\left./ \mathrm{cm}^{2}\right)$

Substituting in the relation $f_{a}=2 f / \pi$ and solving for T yields:

$$
T=\frac{F \pi}{2 f N}
$$

The exposure time per revolution (T) was determined for both the solar and anti-solar sides of the array using the desired fluence $\left(\mathrm{F}_{\text {solar }}=4.4 \times 10^{22}\right.$ atoms $/ \mathrm{cm}^{2}$ and $\mathrm{F}_{\text {antisolar }}=5.2 \times 10^{22}$ atoms $\left./ \mathrm{cm}^{2}\right)$ for each side, the calculated effective flux from the static flux test, and the number of orbits to be simulated $(N=87,660)$. The rotation rate for exposing each side of the array was then determined by taking the inverse of the exposure time:

$$
V=T^{-1}
$$

$\mathrm{V}=$ rate of rotation $(\mathrm{revs} / \mathrm{sec})$ 
The rotational velocities were found to be $\mathrm{V}_{\text {solar }}=0.018 \mathrm{rev} / \mathrm{sec}$, and $\mathrm{V}_{\text {antisolar }}=0.015 \mathrm{rev} / \mathrm{sec}$. Once the rotational velocities were known they were then programmed into the motion control program, so that the rotation rates would result in the correct fluence for each side of the array.

When the rotational velocities had been calculated based on the effective flux from the static flux test, a rotating flux test was conducted. Using the calculated rotation rates, Kapton witness coupons were again mounted on the mock array and exposed in a sweeping arrival process as the actual test would be conducted. Using Equation 1, flux values were calculated for the solar and anti-solar sides of the array. The flux values were found to be $f_{\text {solar }}=1.39 \times 10^{16}$ atoms $/\left(\mathrm{cm}^{2} \cdot \mathrm{sec}\right)$, and $\mathrm{f}_{\text {antisolar }}=1.48 \times 10^{16}$ atoms $/\left(\mathrm{cm}^{2} \cdot \mathrm{sec}\right)$. At this point the flux values found from the rotating flux test could have been used to recalculate the rotational velocities needed to expose the solar and anti-solar side of the array to the same atomic oxygen fluence each rotation as the array will experience through each orbit in space. It was decided though, to avoid making revisions to the motion control program and running a verification flux test that it would acceptable to use the rotational velocities used for the rotating flux test even though it meant that each rotation of the array would result in approximately $17 \%$ less atomic oxygen fluence than in space. Therefore, the test array was exposed to 105,326 revolutions so that the total fluence for the test was the same as required in space even though the expected lifetime of the International Space Station is fifteen years and 87,660 orbits. Based on the values resulting from the rotating flux test, the total side exposure times required to achieve the desired fluence levels were 823.42 hours for the solar side and 974.43 hours for the anti-solar side which resulted in a complete exposure period of 1797.85 hours or 10.7 weeks.

After completing fabrication, the solar array validation coupon's performance was evaluated in Lockheed Martin's Spectrosun Large Area Pulsed Solar Simulator II (LAPSS II) facility. A flash test was performed for each of the two segments which made up the solar array validation coupon. The two segments were designated MPV7-A and MPV7-B. A set of data points was measured and stored for each segment to accurately define the I-V curve of the arrays response before being hinged together and delivered to the NASA Lewis Research Center for the environmental testing.

A complete visual inspection of the test array was performed before installation. Pre-exposure photographs were taken of the array for the purpose of documentation and comparison with postexposure photos. The solar array validation coupon was then installed onto the rotisserie which had been previously mounted in the atomic oxygen facility.

Once the array was installed into the atomic oxygen facility it was tensioned to a static preload of $101.9 \mathrm{~N}(22.9 \mathrm{lbs})$, or $262.8 \mathrm{~N} / \mathrm{m}(1.5 \mathrm{lbs} / \mathrm{in})$ of hinge width at $0.388 \mathrm{~m}(15.29 \mathrm{in})$ as prescribed by Lockheed Martin. The initial tensioning of the array to $262.8 \mathrm{~N} / \mathrm{m}(1.5 \mathrm{lbs} / \mathrm{in})$ was a conservative test load based on the actual expected preload of $140.2 \mathrm{~N} / \mathrm{m}(0.8 \mathrm{lbs} / \mathrm{in})$ which the array blankets will experience when mounted on the solar array wings. After tensioning of the array was set, the system was tested for proper operation. After system check out, the facility was closed and evacuated. 


\section{Exposure Procedures}

The solar array validation coupon was scheduled for 1797.85 hours (10.7 weeks) of exposure to atomic oxygen based on the results of the pretest flux measurements. The elapsed exposure time was measured on a timer linked to the ECR source. Each exposure of the validation array was initiated so that the anti-solar side of the array was exposed first and at the conclusion of each exposure the array was stopped at the end of the solar side's exposure.

Interruptions of the exposure were planned at both the $25 \%$ and $75 \%$ completion points in order to perform a simulated plume loading of the array. A simulated plume loading was performed by applying a static load of $381.0 \mathrm{~N}(85.62 \mathrm{lbs})$, based on $981.1 \mathrm{~N} / \mathrm{m}(5.6 \mathrm{lbs} / \mathrm{in})$ and a hinge width of $0.388 \mathrm{~m}(15.29 \mathrm{in})$, to the array in atmospheric conditions by manually tightening the tension bolt and nut at a rate well below the prescribed maximum tensioning rate of one inch per second. The load was measured using the integral load cell and a multimeter. Once the desired load was reached, it was held for 60 minutes. After the duration of the simulated plume load, the array was relaxed back to a static load of $101.9 \mathrm{~N}(22.9 \mathrm{lbs})$ and atomic oxygen exposure was once again initiated.

Throughout the exposure, operation of the ECR was controlled by a programmable logic controller (PLC) which monitored many permissives or interlocks. If any of the interlocks revealed failure, the operation of the source was discontinued by the controller. The motion control program monitored the operation of the rotisserie and in the event of a mechanical failure the program would send a signal through an input/output board to the ECR's PLC signalling the controller to shut off the source. By halting operation of the ECR source in the event of a mechanical rotation problem, one side of the array would not be exposed to an overdose of atomic oxygen.

\section{Post Exposure Procedures}

After the validation array coupon was exposed to atomic oxygen for a total of 1797.85 hours, it was inspected for any visually apparent damage, degradation or marks. The array was then carefully removed from the mounting structure of the rotisserie and packed in its original shipping package. The array was then transported to a lab where post exposure photographs were taken and a closer visual inspection was performed. After the photographs were taken and the inspection was complete, the array was carefully repackaged and returned to the Lockheed Martin Missiles and Space Company.

A post exposure flux test for the solar and anti-solar side of the array was then performed to determine if there was any significant change in effective flux of atomic oxygen compared to the pre-exposure flux test results. After the atomic oxygen flux was calculated, using the mass loss of Kapton witness sample techniques mentioned earlier, the pre-exposure flux values and post exposure flux values were averaged and used to determine the effective fluence of both the solar and anti-solar sides of the array.

After the array was returned to Lockheed Martin, the output response of each segment of the array was measured in the LAPSS II solar simulation facility as they had been prior to the 
environmental durability testing.

\section{Results and Discussions}

During the array coupon's sweeping exposure to directed atomic oxygen it was tensioned at a load of $101.9 \mathrm{~N}(22.9 \mathrm{lbs})$ of force. After the solar array validation coupon was exposed for 422.55 hours, the $23.5 \%$ completion fluence, it was stopped for a simulated plume loading. The array was subjected to a static tensile load of $381.0 \mathrm{~N}(85.62 \mathrm{lbs})$ which was held for a duration of one hour in atmospheric conditions. Atomic oxygen exposure was then resumed for another 776.3 hours which brought the array's exposure to 1198.85 hours or $66.7 \%$ completion, at which time the second simulated plume load was applied in the same matter as the first. The validation coupon and hinge displayed no signs of deformation or failure during or after either of the performed loadings. Finally, the solar array was exposed to the atomic oxygen environment for the remainder of the 10.7 week period, resulting in a total elapsed time of 1797.85 hours. It was calculated that the solar side of the array was exposed to an effective atomic oxygen fluence of $4.13 \times 10^{22} \pm 5.17 \times 10^{21}$ atoms $/ \mathrm{cm}^{2}(93 \%$ of the desired level \pm the experimental error of $12 \%$ ), and the anti-solar side was exposed to $4.94 \times 10^{22} \pm 6.14 \times 10^{21}$ atoms $/ \mathrm{cm}^{2}$ (95\% of the desired level \pm the experimental error of $\left.12 \%\right)$. These fluence levels were achieved through 105,326 revolutions of the test array.

During the exposure period leading up to the first simulated plume loading, there were several instances in which the system shut down due to mechanical problems stopping the rotation and atomic oxygen exposure. During two of these shut down periods the solar array was exposed to atmospheric conditions while new bearings were installed. These interruptions to the atomic oxygen exposure had no effect on the durability or performance of the array related to the environmental conditions being tested.

A complete visual inspection of the test arrays was performed before and after the solar array validation coupon was removed from the rotisserie and atomic oxygen facility. The coupon had no major abnormalities or degradation. There were adhesive edges which were starting to lift and evidence of atomic oxygen erosion at abraded sites in the protective coating which were not seen before the exposure. Overall, the array visually appeared to survive the complete atomic oxygen exposure with no significant damage.

Post-exposure photograph comparisons with the pre-exposure pictures helped document the degradation of the test array. Figures $6 \mathrm{a}$ and $6 \mathrm{~b}$ show an overall view of the solar and anti-solar side of the array after its exposure to atomic oxygen. It is apparent from these photos that the array had survived the durability testing without any significant damage. Figures 7 and 8 show pre- and post-exposure photos of one of the diodes which was covered with unprotected Kapton. As the photos show, all of the Kapton from the surface was removed by oxidation. The effects of atomic oxygen undercutting can be seen when comparing Figures 9 and 10 which clearly show oxidation at defect sites near the central area of the hinge. Despite the loss of Kapton from the coverlay at this site, the hinge appears intact even after the two tensile loads. The antisolar facing side of the array indicated that atomic oxygen caused significant undercutting at only a few select locations where the protective coating of the coverlay was somehow compromised. The photo in Figure 11 shows the most visible evidence of atomic oxygen erosion in the upper 
middle portion of the array where a wide undercut cavity associated with a scratch or crack type defect in the $\mathrm{SiO}_{x}$ protective coating can be seen.

After the completion of exposing the solar array test coupon to the environmental threats of atomic oxygen and plume loading, the array's functional performance was again tested in a solar simulator. Flash tests were conducted on the two segments MPV7-A and MPV7-B which composed the test array. The I-V response of each segment was recorded and compared to the results of the pre-exposure flash tests. The segment MPV7-A displayed absolutely no change in performance and the segment MPV7-B demonstrated a $2 \%$ reduction in performance. The results of the test can be found in Table 1 . Based on the uncertainty in the measurement using the solar simulator, the $2 \%$ change of the array's output is considered to be little or no degradation of performance.

Even though there was some loss of Kapton due to atomic oxygen attack, the hinge appears intact even after the final tensile loading. This is probably due to the reinforcing fiberglass fabric of the coverlay and also to the protective metal tape covering a majority of the higned region. Undercut defect sites were apparent after the exposure of the array on both the solar and anti-solar facing sides of the array. The most significant undercutting was seen on the antisolar facing surface at locations where the protective coating had been damaged. It is important to note that the array was exposed to atomic oxygen at primarily thermal energies which require a very high flux rate to obtain the same effective fluence as in space. The high flux rates required to obtain the desired effective fluence level results in a greater amount of undercutting than would occur in space. Therefore, testing performed in a thermal energy system is a very conservative method of predicting in-space durability. What is perhaps the most significant finding though was that on the anti-solar facing surface the amount of atomic oxygen damage appeared surprisingly minor with the exception of a very few isolated defects. This indicates that the protective coatings function quite well. However, care still needs to be taken in handling and processing to reduce the probability of generating large defects associated with scratches or cracks.

\section{Summary}

An International Space Station solar array validation coupon was exposed in a directed atomic oxygen beam for space environment durability testing at the NASA Lewis Research Center. The validation coupon was supplied by and tested for Lockheed Martin Missile and Space Company, Incorporated. Atomic oxygen interactions and intermittent plume loading of the solar array were conducted to verify the solar array's durability to the low Earth orbital environment and docking threats which are anticipated over its entire expected mission life.

The solar array coupon was exposed to atomic oxygen at a tensile load of $101.9 \mathrm{~N}$ ( $22.9 \mathrm{lbs}$ ), through 105,326 revolutions, over a period of 1797.85 hours. The array was mounted in a specially designed rotisserie which was driven by a stepper motor, drive, and motion control software, providing motion to a chain and sprocket system. This allowed the coupon to be rotated while under tensile loading at two discrete rotational speeds so that each side of the array could be exposed to atomic oxygen for a different amount of time. The effective fluence levels 
for the test based on Kapton mass loss were calculated to be $4.13 \times 10^{22} \pm 5.17 \times 10^{21}$ atoms $/ \mathrm{cm}^{2}$, for the solar facing side and $4.93 \times 10^{22} \pm 6.14 \times 10^{21}$ atoms $/ \mathrm{cm}^{2}$ for the anti-solar facing side of the array.

The durability of the solar array and most importantly its hinge region to the docking threat of plume loading was also tested. At two times during its exposure the array was subjected to a tensile load of $381.0 \mathrm{~N}(85.62 \mathrm{lbs})$. The first tensile load was applied after 422.55 hours of exposure (23.5\% completion of the total exposure) and the second was applied after a total of 1198.85 hours $(66.7 \%$ completion) with each being held for a period of 60 minutes in atmospheric conditions. The validation coupon and hinge displayed no signs of deformation or failure during either of the simulated plume loadings.

Flash tests in a solar simulator were also conducted before and after the exposure period on the two segments MPV7-A and MPV7-B which composed the test array. The I-V response of each segment was recorded and compared to the previous results. The segment MPV7-A displayed absolutely no change in performance and the segment MPV7-B demonstrated a $2 \%$ reduction in performance.

Photographs were taken of the solar array both before and after the exposure period allowing for comparison and documentation of the effects which the tests had on the array. The amount of atomic oxygen damage appeared minor with the exception of a very few isolated defects. There were also no indications that the simulated plume loadings had weakened or damaged the array, even though there was some erosion of Kapton due to atomic oxygen attack.

It is apparent based on the results of this testing that the International Space Station solar arrays should survive the low Earth orbital and docking threats which are anticipated over its expected mission life of fifteen years. Also based on the results of the solar simulation flash testing it is believed that during their lifetime the solar arrays should experience very little or no degradation of performance due to atomic oxygen attack.

\section{Acknowledgements}

The authors would like to acknowledge the contributions made to this effort by Charles Pennington whose advice and assistance was invaluable. 


\section{References}

1. J. A. Dever, "Low Earth Orbital Atomic Oxygen and Ultraviolet Radiation Effects on Polymers," NASA Technical Memorandum 103711, February 1991.

2. B. A. Banks, et.al., "Atomic Oxygen Interaction with Solar Array Blankets at Protective Coating Defect Sites, " Paper for the Fourth Annual Workshop on Space Operations Automation and Robotics (SOAR), Albuquerque, New Mexico, June 26$28,1990$.

3. J.T. Visentine and L.J. Leger, "Material Interactions with the Low Earth Orbital Environment: Accurate Reaction Rate Measurements", JPL Publication 87-14, pp1120, November 1986.

4. B. Smith, and H. Brisco, "Solar Array Electrical Performance Assessment for Space Station Freedom ", NASA Technical Memorandum 106161, Prepared for the Aerospace Design Conference sponsored by the AIAA, AHS, and ASEE, Irvine, CA, February 16-19, 1993.

5. B. A. Banks, S. K. Rutledge, L. Gebauer, and C. LaMoreaux, "SiOx Coatings for Atomic Oxygen Protection of Polyimide Kapton in Low Earth Orbit", AIAA 92-2151, 1992

6. S. K. Rutledge, and Raymond Olle, "Space Station Freedom Solar Array Blanket Coverlay Atomic Oxygen Durability Testing Results", 38th International SAMPE Symposium, Anaheim, CA, May 10-13, 1993

7. B. A. Banks, et.al., "The Use of Plasma Ashers and Monte Carlo Modeling for the Projection of Atomic Oxygen Durability of Protected Polymers in Low Earth Orbit", 17th Space Simulation Conference, Baltimore, MD, November 9-12, 1992

8. J. F. Shaker, and T. H. Acquaviva, "Static Stability of the Space Station Solar Array FASTMast Structure", NASA Technical Memorandum 106895, August 1995.

9. C. R. Stidham, et. al., "Low Earth Orbital Atomic Oxygen Environment Simulation Facility for Space Materials Evaluation", NASA Technical Memorandum 106128, Prepared for the 38th International SAMPE Symposium, Anaheim, CA, May 10-13, 1993

10. B. B. Banks, et. al., "Atomic Oxygen Durability evaluation of Protected Polymers Using Thermal Energy Plasma Systems", Paper for presentation at the International Conference of Plasma Synthesis and Processing of Materials, Denver, CO, February 21-25, 1993. 
11. L. G. Leger, B. Santos-Mason, J. T. Visintine and J. F. Kuminecz, "Review of LEO Flight Experiments", in Proceedings of the NASA Workshop on Atomic Oxygen Effects, D. E. Brinza, ed., NASA CR-181163 (NASA Washington DC, 1987) pp. 110, November, 1986.

12. L. G. Leger, "Oxygen Atom Reaction with Shuttle Materials at Orbital Altitudes Data and Experiment Status", AIAA Paper 83-0073, January, 1983.

13. L. G. Leger, I. K. Spiker, J. F. Kuminecz, T. J. Ballentine, and J. T. Visentine, "STS Flight 5 LEO Effects Experiment -- Backgroud Description and Thin Film Results", AIAA Paper 83-2361-CP, November, 1983.

14. J. T. Visentine, L. G. Leger, J. F. Kuminecz, and I. K. Spiker," STS-8 Atomic Oxygen Effects Experiment", AIAA Paper 85-0415, January, 1985.

15. D. R. Coulter, R. H. Liang, S. H. Chung, K. O. Smith, and A. Grupta, " O-Atom Degradation Mechanisms of Materials", in Proceedings of the NASA Workshop on Atomic Oxygen Effects, D. E. Brinza, ed., NASA CR-181163 (NASA Washington DC, 1987) pp. 1-10, November, 1986. 
TABLE I. FLASH TEST RESULTS OF THE SOLAR ARRAY VALIDATION COUPON

\begin{tabular}{|c|c|c|c|c|}
\hline \multirow[t]{3}{*}{ Attribute } & $\begin{array}{l}\text { Baseline } \\
5 \text { Jan } 94\end{array}$ & $\begin{array}{c}\text { After } 100 \% \\
\text { total } \\
\text { AO exposure } \\
23 \text { Jan } 96\end{array}$ & $\begin{array}{l}\text { Baseline } \\
5 \text { Jan } 94\end{array}$ & $\begin{array}{c}\text { After } 100 \% \\
\text { total } \\
\text { AO exposure } \\
23 \text { Jan } 96\end{array}$ \\
\hline & \multicolumn{2}{|c|}{ Absolute Values } & \multicolumn{2}{|c|}{ Delta from Baseline } \\
\hline & \multicolumn{4}{|c|}{ MPV7-A } \\
\hline $\begin{array}{l}\text { Isc (Amps) } \\
\text { Voc (Volts) } \\
\text { Itp (Amps) @ } 3.845 \text { volts } \\
\text { Ipmx (Amps) } \\
\text { Vpmx (Volts) } \\
\text { Pmax (watts) } \\
\text { FillFactor }\end{array}$ & $\begin{array}{l}2.589 \\
4.943 \\
2.356 \\
2.376 \\
3.811 \\
9.054 \\
0.708\end{array}$ & $\begin{array}{l}2.558 \\
4.939 \\
2.356 \\
2.397 \\
3.778 \\
9.058 \\
0.709\end{array}$ & $\begin{array}{l}0.00 \% \\
0.00 \% \\
\mathbf{0 . 0 0 \%} \\
0.00 \% \\
0.00 \% \\
0.00 \% \\
0.00 \%\end{array}$ & $\begin{array}{c}1.20 \% \\
0.08 \% \\
\mathbf{0 . 0 0 \%} \\
-0.88 \% \\
0.87 \% \\
-0.04 \% \\
-0.14 \% \\
\end{array}$ \\
\hline FillFactor & \multicolumn{4}{|c|}{ MPV7-B } \\
\hline $\begin{array}{l}\text { Isc (Amps) } \\
\text { Voc (Volts) } \\
\text { Itp (Amps) @ } 3.845 \text { volts } \\
\text { Ipmx (Amps) } \\
\text { Vpmx (Volts) } \\
\text { Pmax (watts) } \\
\text { FillFactor }\end{array}$ & $\begin{array}{l}2.588 \\
4.886 \\
2.347 \\
2.373 \\
3.802 \\
9.021 \\
0.714\end{array}$ & $\begin{array}{l}2.604 \\
4.856 \\
2.301 \\
2.392 \\
3.716 \\
8.887 \\
0.703\end{array}$ & $\begin{array}{l}0.00 \% \\
0.00 \% \\
\mathbf{0 . 0 0 \%} \\
0.00 \% \\
0.00 \% \\
0.00 \% \\
0.00 \%\end{array}$ & $\begin{array}{l}-0.62 \% \\
0.61 \% \\
1.96 \% \\
-0.80 \% \\
2.26 \% \\
1.49 \% \\
1.54 \% \\
\end{array}$ \\
\hline
\end{tabular}




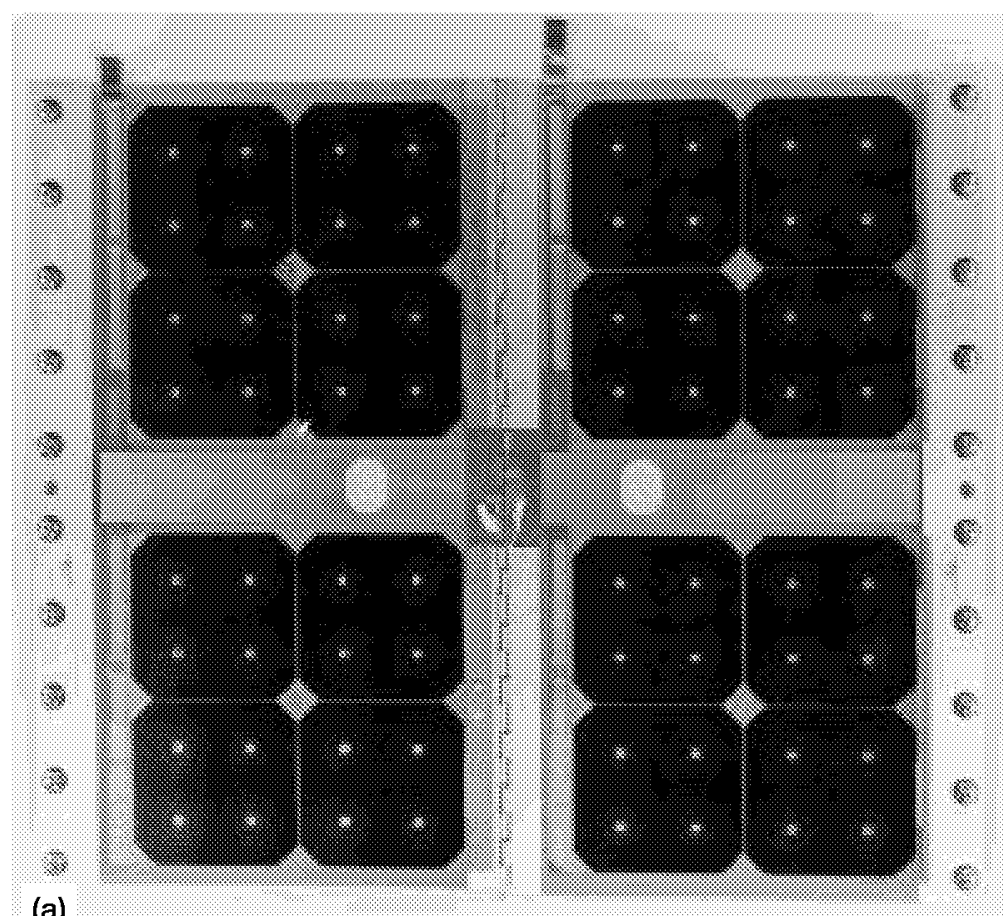

(a)

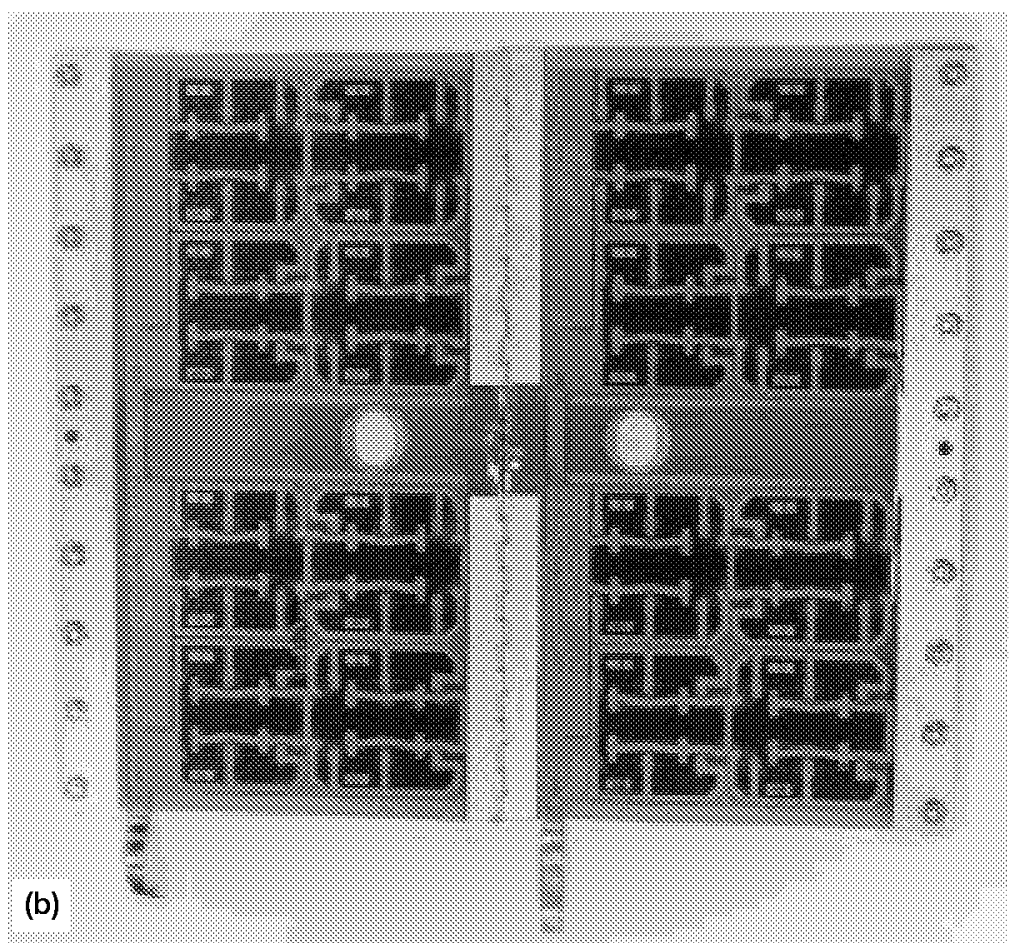

Figure 1.-Solar array validation coupon before exposure to atomic oxygen and tensile loading: (a) solar side and (b) anti-solar side. 


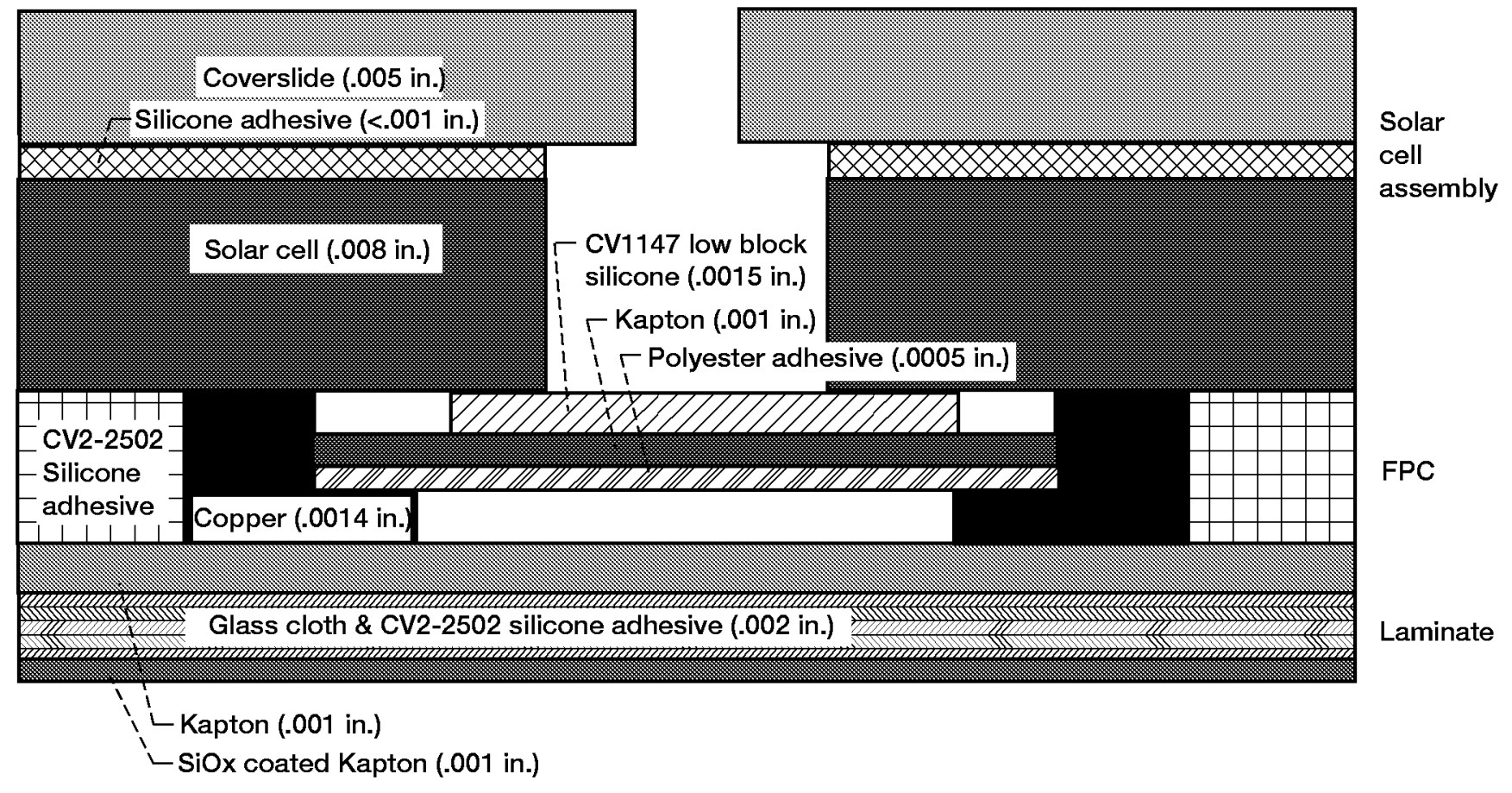

Figure 2.-Cross section of space station solar panel.

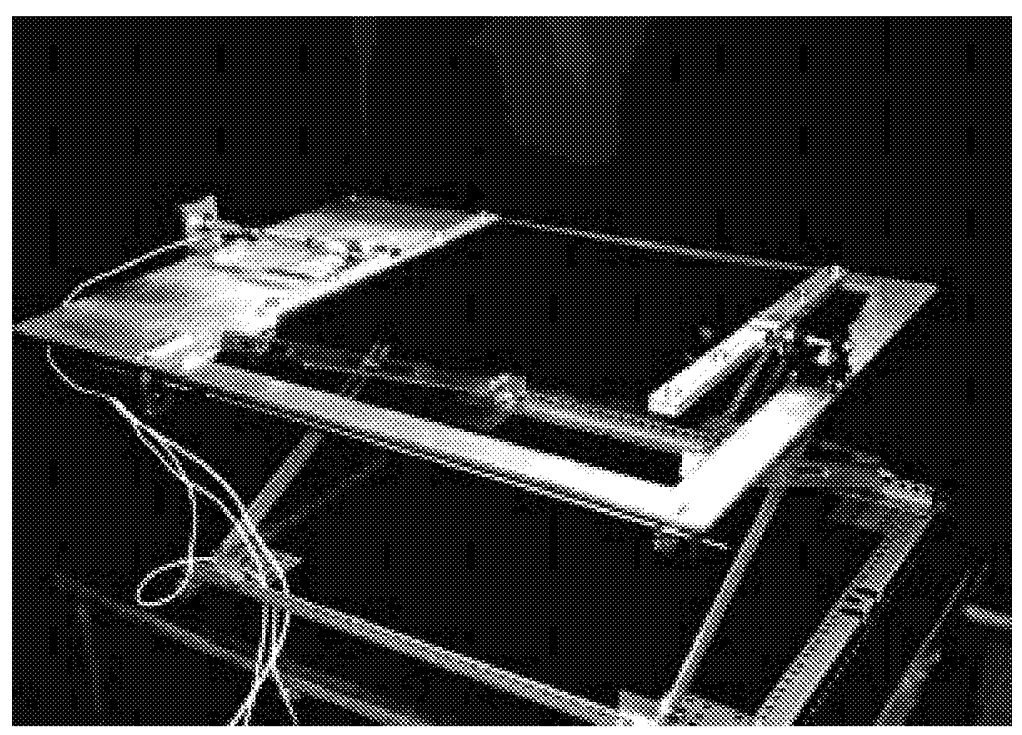

Figure 3.-Mounting rotisserie for the solar array validation coupon testing. 


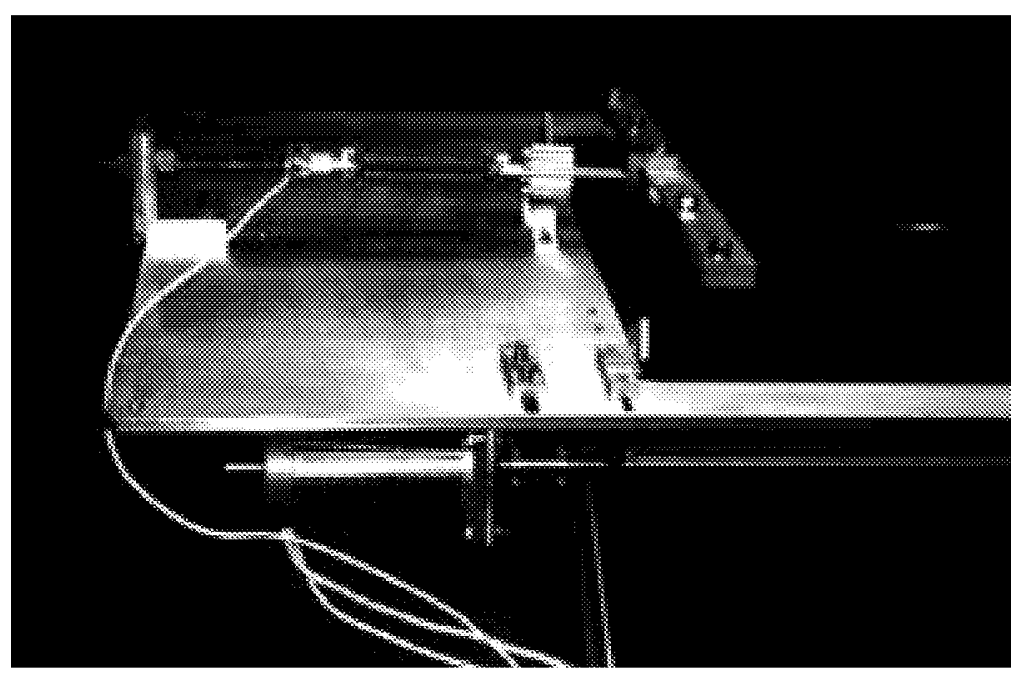

Figure 4.-Apparatus for tensioning to the array.

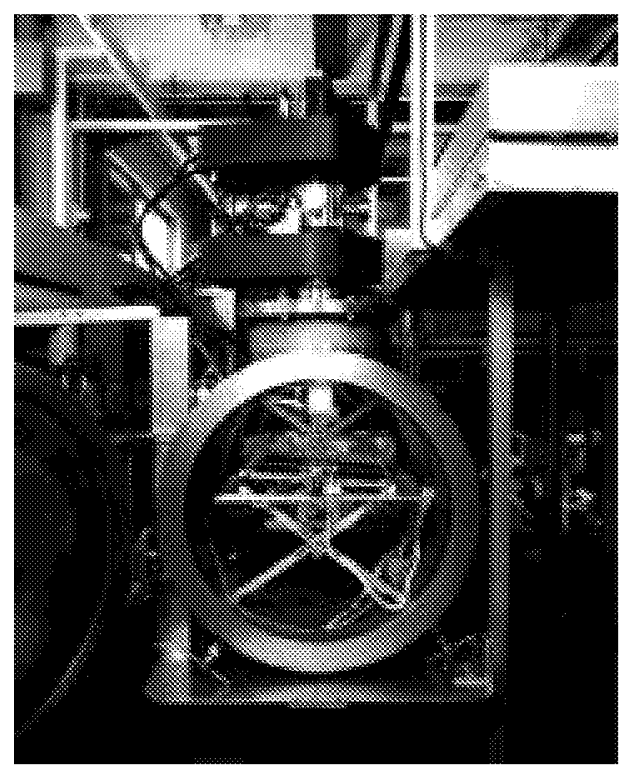

Figure 5.-Solar array validation coupon mounted in the rotisserie and ready for testing in the NASA Lewis Research Center's atomic oxygen facility. 


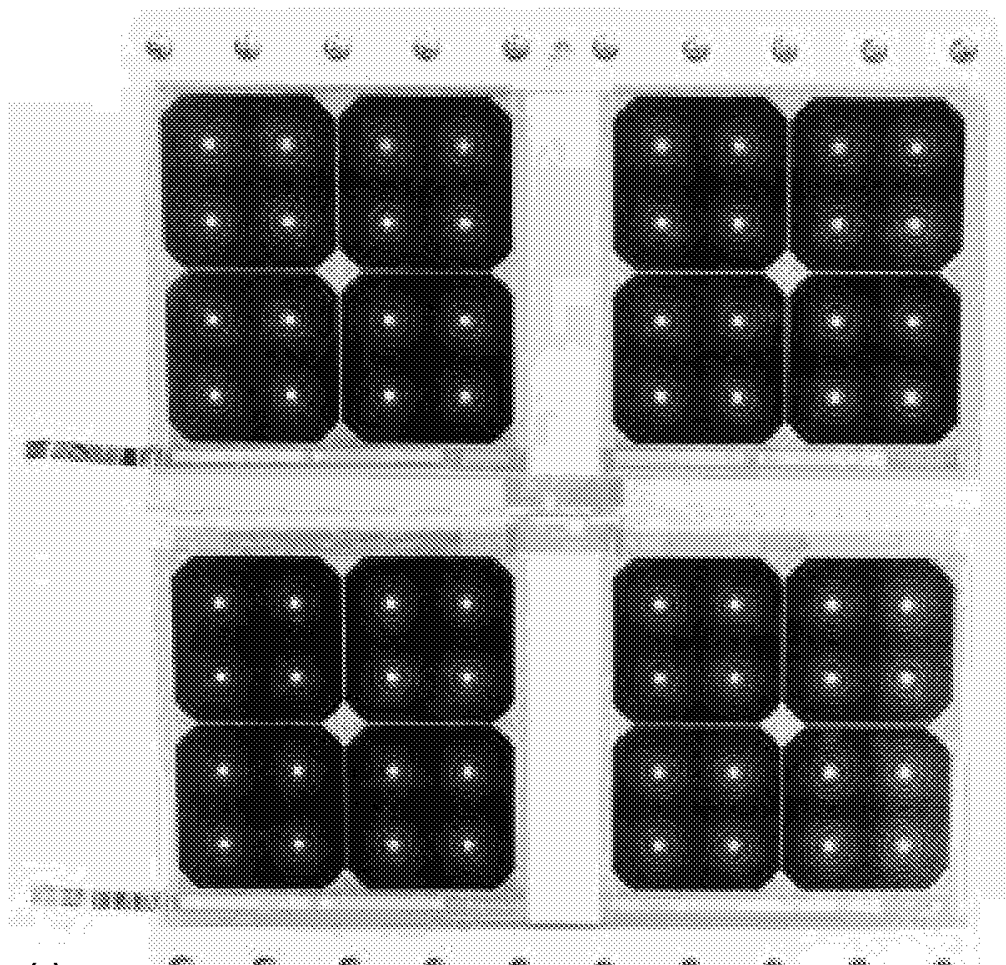

(a)
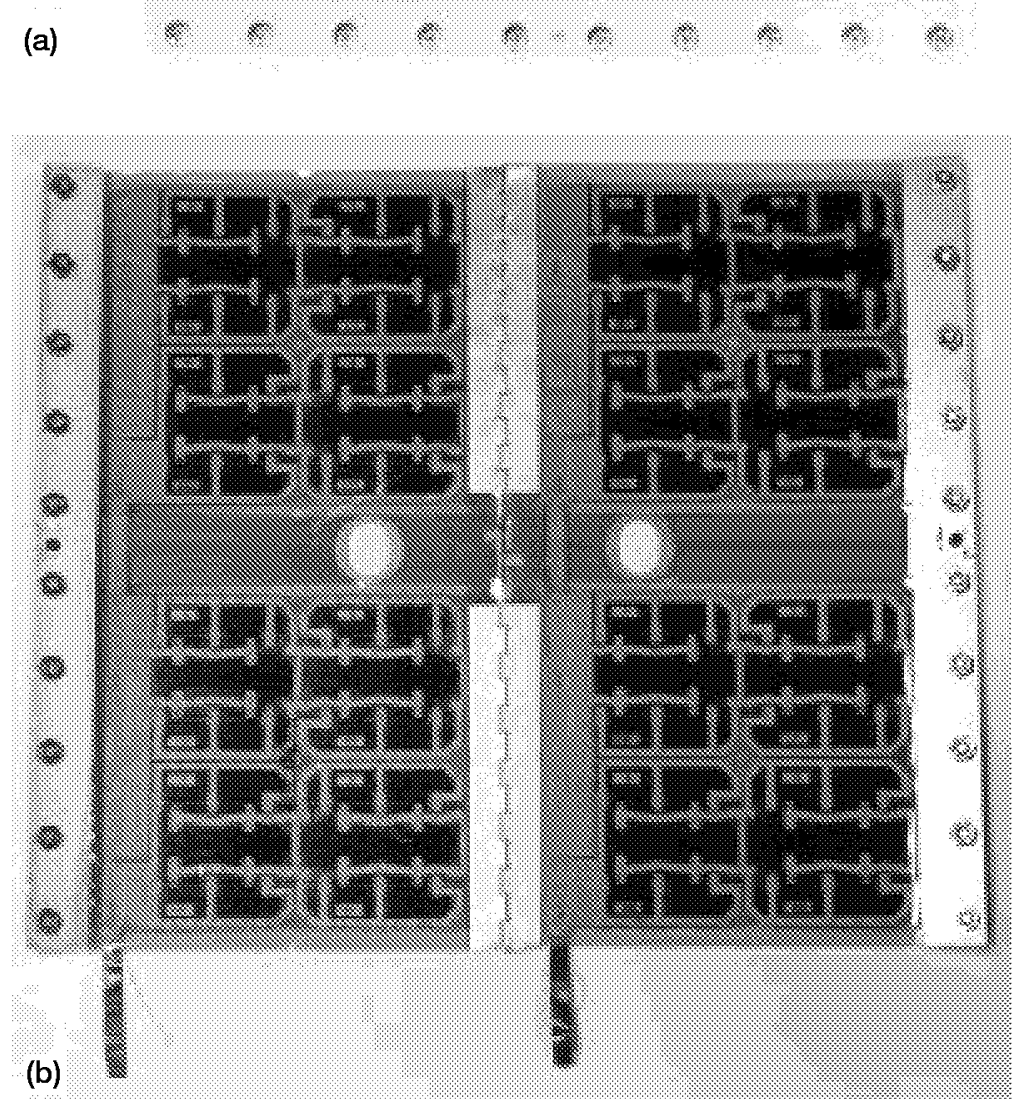

Figure 6.-Solar array validation coupon after exposure to atomic oxygen and tensile loading: (a) solar side and (b) anti-solar side. 


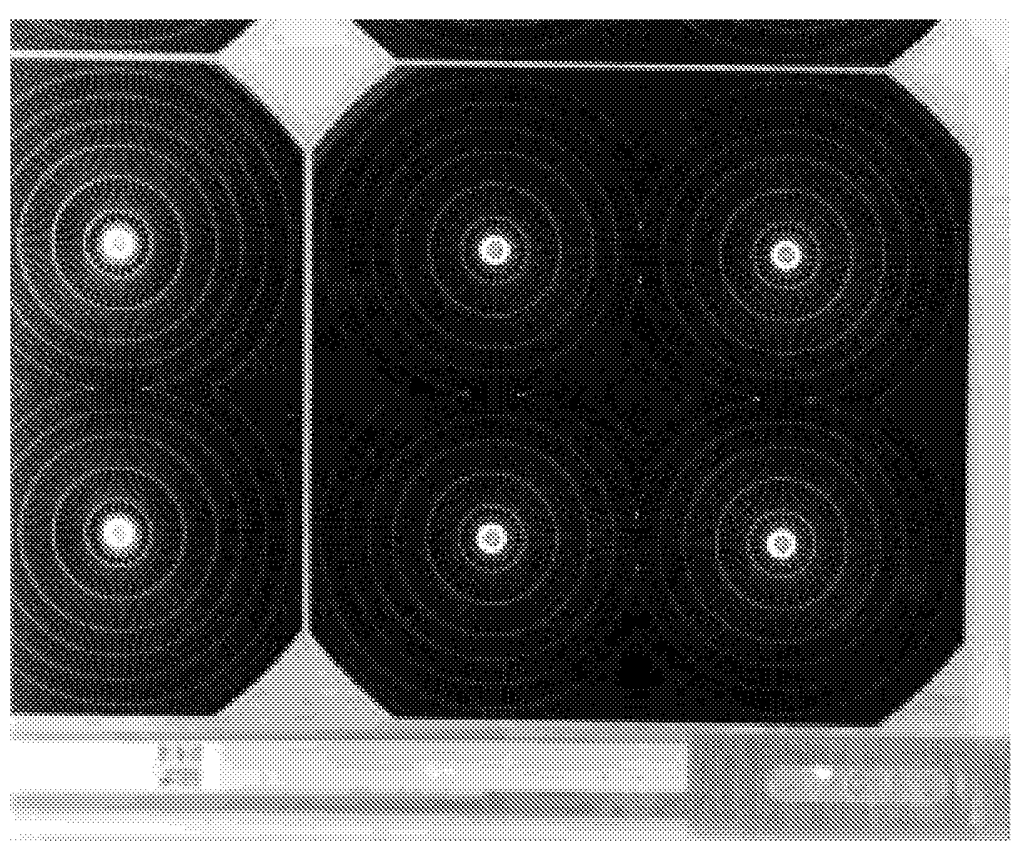

Figure 7.-Photo of the solar array showing a close up of solar cell and diode prior to exposure to atomic oxygen and tensile loading.

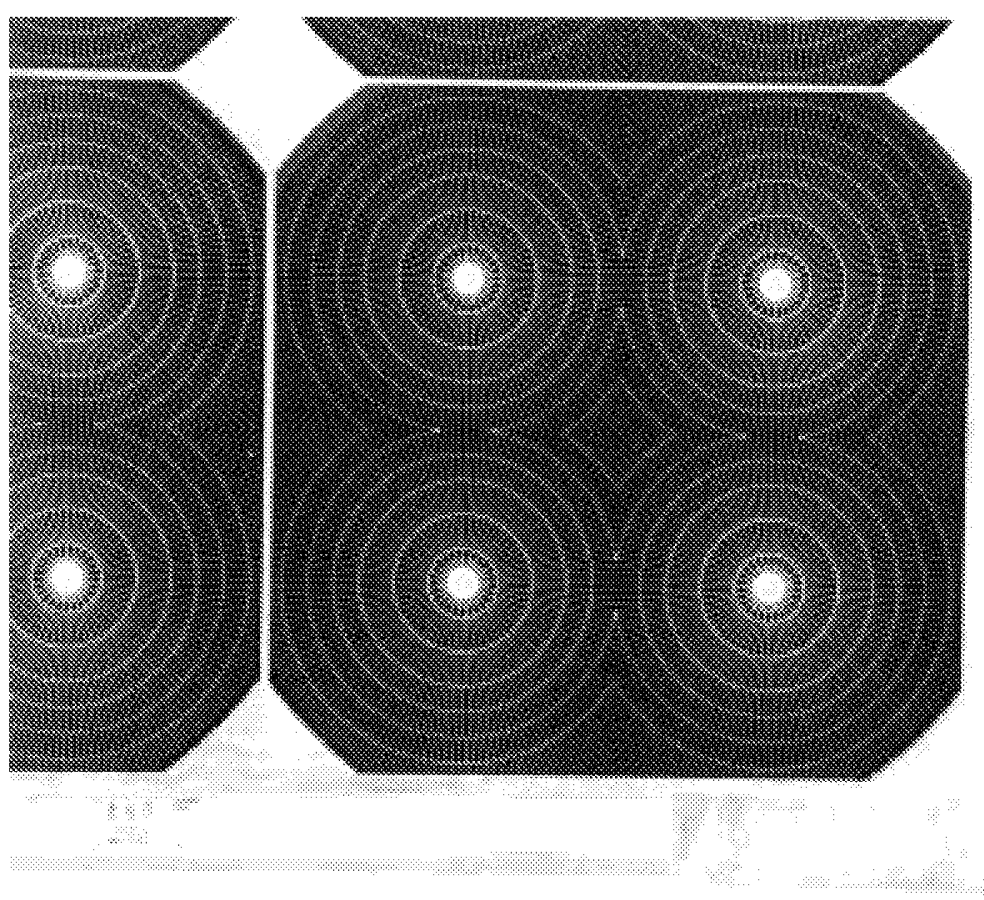

Figure 8.-Photo of the solar array showing a close up of solar cell and diode after exposure to atomic oxygen and tensile loading. 


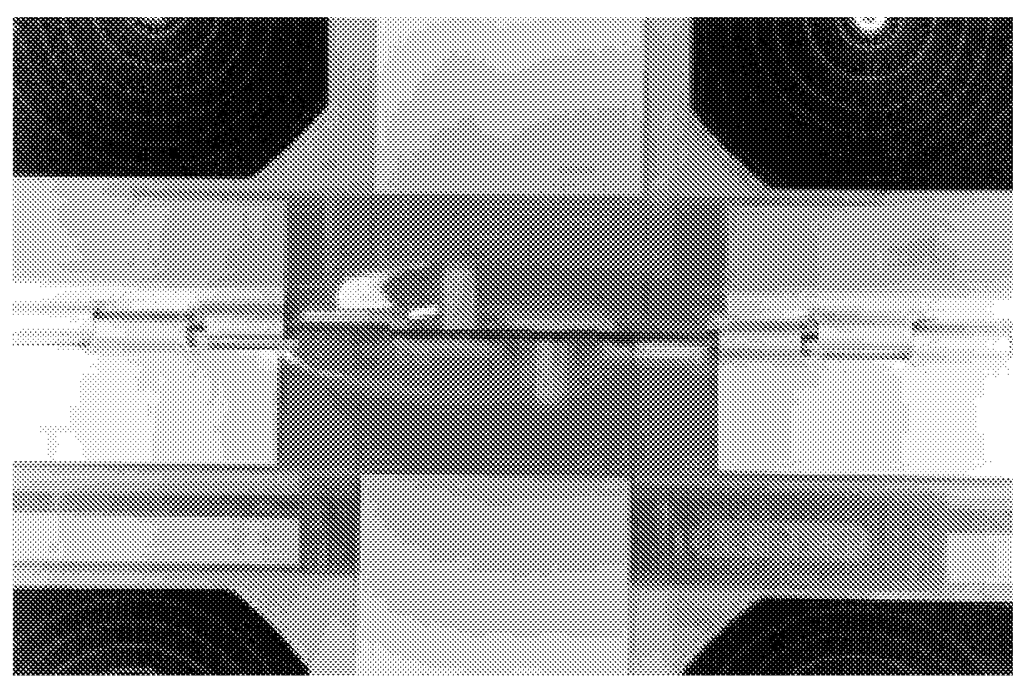

Figure 9.-Central hinge region of the solar array validation coupon prior to exposure to atomic oxygen and tensile loading.

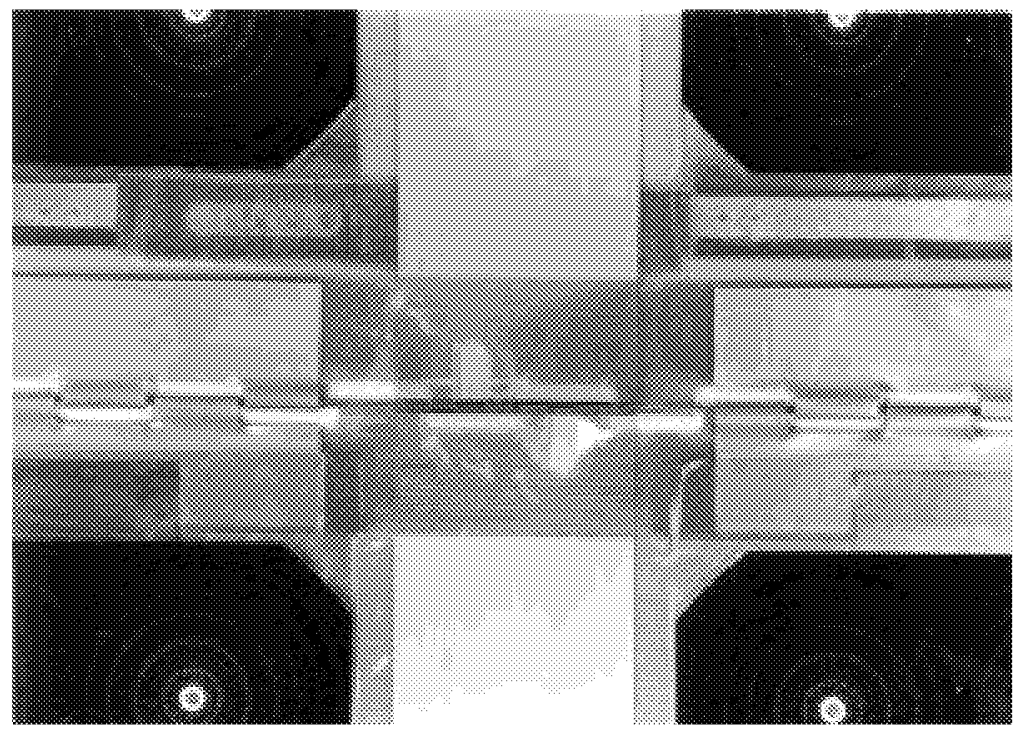

Figure 10.-Central hinge region of the solar array validation coupon after to exposure to atomic oxygen and tensile loading. 


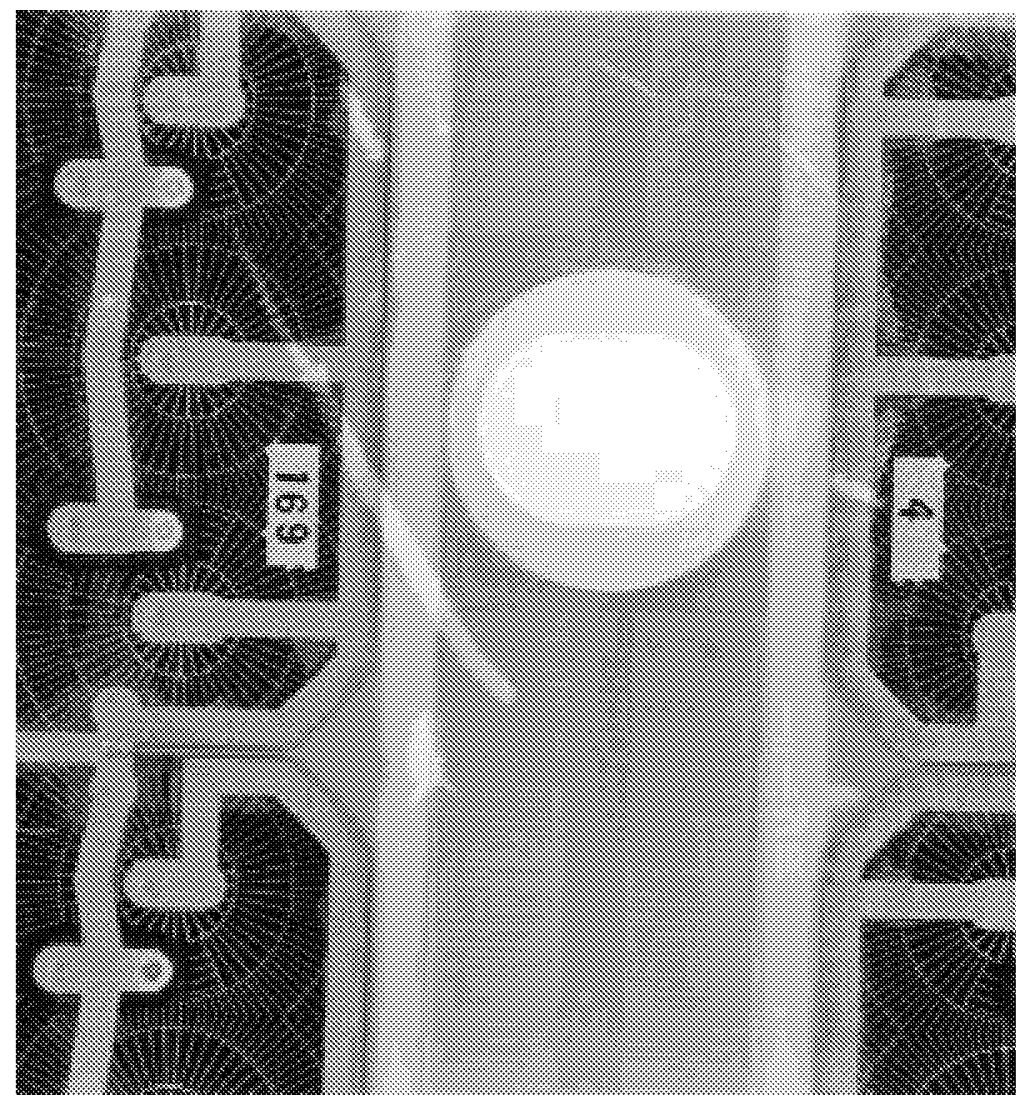

Figure 11.-Evidence of atomic oxygen attack on the anti-solar side of the array after full fluence exposure. 
Public reporting burden for this collection of information is estimated to average 1 hour per response, including the time for reviewing instructions, searching existing data sources gathering and maintaining the data needed, and completing and reviewing the collection of information. Send comments regarding this burden estimate or any other aspect of this collection of information, including suggestions for reducing this burden, to Washington Headquarters Services, Directorate for Information Operations and Reports, 1215 Jefferson Davis Highway, Suite 1204, Arlington, VA 22202-4302, and to the Office of Management and Budget, Paperwork Reduction Project (0704-0188), Washington, DC 20503.
1. AGENCY USE ONLY (Leave blank)
2. REPORT DATE
3. REPORT TYPE AND DATES COVERED
April 1996
Technical Memorandum

4. TITLE AND SUBTITLE

5. FUNDING NUMBERS

Atomic Oxygen Durability Testing of an International Space Station Solar Array Validation Coupon

6. AUTHOR(S)

WU-233-1A-1E

Mark J. Forkapa, Curtis R. Stidham, Bruce A. Banks, Sharon K. Rutledge, David H. Ma, and Edward A. Sechkar

7. PERFORMING ORGANIZATION NAME(S) AND ADDRESS(ES)

8. PERFORMING ORGANIZATION REPORT NUMBER

National Aeronautics and Space Administration

Lewis Research Center

Cleveland, Ohio 44135-3191

$\mathrm{E}-10229$

9. SPONSORING/MONITORING AGENCY NAME(S) AND ADDRESS(ES)

10. SPONSORING/MONITORING AGENCY REPORT NUMBER

National Aeronautics and Space Administration

Washington, D.C. 20546-0001

NASA TM-107212

\section{SUPPLEMENTARY NOTES}

Prepared for the Third International Conference on Protection of Materials and Structures from the Low Earth Orbit Space Environment sponsored by the University of Toronto, Toronto, Canada, April 25-26, 1996. Mark J. Forkapa and Curtis R. Stidham, NYMA, Inc., 2001 Aerospace Parkway, Brook Park, Ohio 44142 (work performed under NASA Contract NAS3-27186); Bruce A. Banks and Sharon K. Rutledge, NASA Lewis Research Center; David H. Ma, Lockheed Martin Missiles \& Space Company, Sunnyvale, California; Edward A. Sechkar, Cleveland State University, Cleveland, Ohio 44115. Responsible person, Mark J. Forkapa, organization code 5480, (216) 433-2299.

12a. DISTRIBUTION/AVAILABILITY STATEMENT

12b. DISTRIBUTION CODE

Unclassified - Unlimited

Subject Category 12

This publication is available from the NASA Center for AeroSpace Information, (301) 621-0390.

13. ABSTRACT (Maximum 200 words)

An International Space Station solar array validation coupon was exposed in a directed atomic oxygen beam for space environment durability testing at the NASA Lewis Research Center. Exposure to atomic oxygen and intermittent tensioning of the solar array were conducted to verify the solar array's durability to low Earth orbital atomic oxygen and to the docking threat of plume loading both of which are anticipated over its expected mission life of fifteen years. The validation coupon was mounted on a specially designed rotisserie. The rotisserie mounting enabled the solar and anti-solar facing side of the array to be exposed to directed atomic oxygen in a sweeping arrival process replicating space exposure. The rotisserie mounting also enabled tensioning, in order to examine the durability of the array and its hinge to simulated plume loads. Flash testing to verify electrical performance of the solar array was performed with a solar simulator before and after the exposure to atomic oxygen and tensile loading. Results of the flash testing indicated little or no degradation in the solar array's performance. Photographs were also taken of the array before and after the durability testing and are included along with comparisons and discussions in this report. The amount of atomic oxygen damage appeared minor with the exception of a very few isolated defects. There were also no indications that the simulated plume loadings had weakened or damaged the array, even though there was some erosion of Kapton due to atomic oxygen attack. Based on the results of this testing, it is apparent that the International Space Station's solar arrays should survive the low Earth orbital atomic oxygen environment and docking threats which are anticipated over its expected mission life.

\section{SUBJECT TERMS}

Atomic oxygen; Low Earth Orbit; International Space Station; Solar array; Protected polymers; Kapton; Photovoltaic

\begin{tabular}{|c|c|c|c|}
\hline $\begin{array}{c}\text { 17. SECURITY CLASSIFICATION } \\
\text { OF REPORT } \\
\text { Unclassified }\end{array}$ & $\begin{array}{c}\text { 18. SECURITY CLASSIFICATION } \\
\text { OF THIS PAGE } \\
\text { Unclassified }\end{array}$ & $\begin{array}{c}\text { 19. SECURITY CLASSIFICATION } \\
\text { OF ABSTRACT } \\
\text { Unclassified }\end{array}$ \\
\hline
\end{tabular}

\begin{tabular}{|c|} 
15. NUMBER OF PAGES \\
23 \\
\hline $\begin{array}{c}\text { 16. PRICE CODE } \\
\text { A03 }\end{array}$ \\
20. LIMITATION OF ABSTRACT \\
\end{tabular}

